\title{
Políticas para el desarrollo de las zonas más afectadas por el conflicto (ZOMAC)
}

\author{
Luis Carlos Sandoval Vásquez \\ Dirección de Impuestos y Aduanas Nacionales \\ Colombia \\ Jesús Augusto Torra Cárdenas \\ Dirección de Impuestos y Aduanas Nacionales \\ Colombia \\ María Ana Martina Chía Suarez \\ Universidad Santo Tomás \\ Colombia
}




\title{
Políticas para el desarrollo de las zonas más afectadas por el conflicto (ZOMAC)
}

\author{
Luis Carlos Sandoval Vásquez ${ }^{\circledR}$, Jesús Augusto Torra Cárdenas ${ }^{2} \mathbb{D}$, y María Ana \\ Martina Chía Suarez ${ }^{1}$ iD \\ 1 Universidad Santo Tomás, Colombia \\ 2 Dirección de Impuestos y Aduanas Nacionales, Colombia
}

Para citaciones: Sandoval, L. Torra, J. Chía M. (2020). Políticas para el desarrollo de las zonas más afectadas por el conflicto (ZOMAC). Panorama Económico, 28(2), 102115. https://doi.org/10.32997/pe-2020$\underline{2692}$

Recibido: $12 / 07 / 2019$

Aprobado: 17/11/2019

Autor de correspondencia: María Ana Martina Chía Suarez mariana-chia@hotmail.com

Editor: Andrés Escobar Espinoza Universidad de Cartagena, Colombia

Tipología IBN Publindex: Artículo de Reflexión

Copyright: (C) 2020. Sandoval, L. Torra, J. Chía M. Este es un artículo de acceso abierto, distribuido bajo los términos de la licencia https://creativecommons.org/licenses/by-

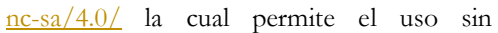
restricciones, distribución y reproducción en cualquier medio, siempre y cuando que el original, el autor y la fuente sean acreditados.

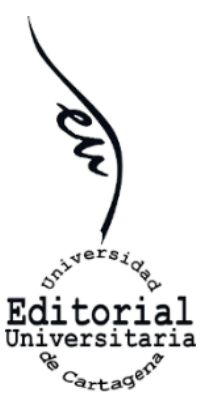

\section{RESUMEN}

El conflicto armado en Colombia ha dejado secuelas económicas y sociales, en especial en territorios dominados durante décadas por los grupos ilegales. Con la firma del acuerdo de paz, entre el Estado y las Fuerzas Armadas Revolucionarias de Colombia (FARC), el gobierno nacional creó las Zonas Más Afectadas por el Conflicto (ZOMAC), con el propósito de garantizar el desarrollo en estos territorios y atraer la inversión nacional e internacional, y avanzar así en la descentralización industrial y contribuir al bienestar de sus pobladores de manera sostenible. Este documento analiza las condiciones fiscales, económicas y sociales, necesarias para promover el desarrollo sostenible en aquellas zonas conforme al marco fiscal que las genera. Para este fin, se analizan fuentes documentales disponibles, que logren precisar tendencias internacionales de procesos que hayan permitido estimular la inversión y desarrollo de comunidades afectadas y excluidas de la política de desarrollo económico nacional. Finalmente, la reflexión concluye analizando la situación del municipio de Aguachica (Departamento del Cesar) con el fin de contribuir al desarrollo regional de las ZOMAC.

Palabras clave: Política fiscal; Desarrollo regional; Conflicto Armado; Postconflicto; ZOMAC. JEL: O10, O18, O21

\section{Development policies for the Colombian zones most affected by conflict (ZOMAC)}

\section{ABSTRACT}

The armed conflict in Colombia has had economic and social consequences, especially in territories dominated for decades by illegal groups. With the signing of the peace agreement between the State and the Revolutionary Armed Forces of Colombia (FARC), the national government created the Zones Most Affected by the Armed Conflict (ZOMAC), with the purpose of guaranteeing development in these territories, attracting national and international investment, advance in industrial decentralization and contribute to the well-being of its inhabitants in a sustainable way. This article analyzes the fiscal, economic and social conditions necessary to promote sustainable development in those areas in accordance with the fiscal framework that generates them. To this end, available documentary sources are analyzed, which succeed in specifying international trends in processes promoting investment and development in communities affected and excluded from the national economic development policy. Finally, it concludes analyzing the situation of the municipality of Aguachica (Cesar) in order to contribute to the regional development of the ZOMACs.

Key words: Fiscal policy; regional development; armed conflict; post-conflict; ZOMAC. JEL: O10, O18, O21 


\section{INTRODUCCIÓN}

El estado colombiano, vivió por más de 50 años un conflicto interno que generó desigualdad y temor en las comunidades, con mayor énfasis en aquellas que vivieron el abandono estatal de primera mano, desincentivando la inversión en estos territorios lo que atrasó en gran parte su desarrollo económico. Con el acuerdo final para la terminación del conflicto se trataron ciertos puntos; uno de estos dio lugar a "la reforma rural integral" con la cual se busca contribuir al cambio integral del campo, disminuyendo la desigualdad entre las zonas rurales y las zonas urbanas y generando un estado de confort y tranquilidad a la población campesina.

La Ley 1819 en su aparte XI establece beneficios fiscales para aminorar la desigualdad socioeconómica fomentado el empleo y la formalización de las comunidades rurales y de las minorías étnicas. El primer incentivo consiste en un beneficio progresivo en el impuesto a la renta y complementarios para empresas que se creen en las zonas afligidas por el conflicto; el segundo, es la posibilidad de destinar hasta un 50\% del impuesto a cargo en renta, a el desarrollo de proyectos de infraestructura pública priorizados en viabilizados y priorizados en los municipios ubicados en las ZOMAC. Dentro de la metodología de investigación, se precisaron tendencias que estimularon la inversión y el avance hacia un desarrollo sostenible en comunidades afectadas no solo por el conflicto o por estar apartadas del casco urbano, sino también por desastres naturales que las alejaron del desarrollo; en el proceso de entrevistas, se formularon preguntas acerca de los factores fundamentales para lograr el desarrollo del municipio de Aguachica, la forma más adecuada de incorporar y articular a Aguachica a la política de inversión del país y desarrollo empresarial, el aporte de los beneficios tributarios a los precios en productos competitivos a nivel internacional y la eficiencia de las políticas fiscales frente a las ZOMAC para la recuperación y desarrollo del sector agrícola, la agroindustria y el municipio; preguntas que apuntaron hacia un panorama de alternativas y propuestas que contribuyen al cierre de brechas económicas y sociales y al desarrollo sostenible de este municipio.

El presente artículo analiza el desarrollo económico en regiones apartadas y en especial el desarrollo de las denominadas zonas afectadas por el conflicto (ZOMAC), desde una óptica que permita corroborar la importancia que tiene para un desarrollo sostenible la aplicación de políticas fiscales, en conjunto con políticas económicas y sociales; de igual manera pretende establecer particularidades necesarias que garanticen y avalen las inversiones, haciendo estas inversiones sostenibles y confiables en cada uno de estos territorios.

\section{IMPORTANCIA DE LA POLÍTICA FISCAL EN LA RECONSTRUCCIÓN DE ÁREAS MENOS PRIVILEGIADAS}

Es importante responder ¿qué es y cómo funciona la política fiscal?; este término hace referencia a la administración tanto del gasto público, como de los ingresos, que en su mayoría provienen de los impuestos. Una política fiscal debe realizarse de manera eficiente permitiendo influir en la producción nacional, el empleo y el nivel de precios, en otras palabras, facilita el desempeño de la economía nacional, generando crecimiento y desarrollo económico, social, ambiental y político. (Banco de la República, 2017) 
Para Bangs (1971), la política fiscal es una de las herramientas más poderosas en el conjunto de políticas gubernamentales que los países tienen para contrarrestar las perturbaciones cíclicas de la economía, cuyas implicaciones a largo plazo abarcan los efectos sobre la tasa de crecimiento económico de un país. Si bien es cierto, para generar crecimiento económico se requiere inversión pública, en transporte, servicios, agricultura, educación y otros sectores que aseguran el crecimiento; la inversión pública por sí sola no asegura el éxito del crecimiento, siendo necesario que ésta se complemente con inversión privada que se hace presente en nuevas o empresas ya existentes que añaden magnitud y diversificación a la corriente de bienes y servicios terminados.

Como menciona Bangs (1971): "Incluso si la política nacional decreta que deben ofrecerse concesiones a la inversión privada, no es necesario que estas asuman la forma de concesiones impositivas, podrían emplearse subsidios directos $u$ ofrecerse créditos en términos favorables" (p.117). Según el Banco de la República (2013), los objetivos de la política fiscal se centran en controlar los ciclos económicos, reducir el desempleo, la redistribución del ingreso, la elevación del nivel de ingreso nacional, entre otras, pero enfatiza en que la consecución de estos objetivos estará condicionada por los objetivos generales que persigue en determinado momento el gobierno nacional por su política económica.

Las políticas fiscales parten del plan de desarrollo de cada gobierno, cada uno de estos basados en las necesidades que perciben los gobiernos de turno. Cabe resaltar que estas no solo son un instrumento que controla el ciclo económico, sino que también pretenden reducir la inequidad y alcanzar un desarrollo sostenible. Teniendo en cuenta que las Zonas más Afectadas por el Conflicto (ZOMAC), fueron creadas bajo el tratado de paz entre el Gobierno de Colombia y las Fuerzas Armadas Revolucionarias de Colombia (FARC), el Gobierno Nacional será quien se encargue de dirimir el futuro de estas zonas, por medio de su plan de gobierno y desarrollo. Lo anterior, representa una ardua tarea de plantear herramientas, mecanismos y oportunidades para el inicio de actividades no solo en dichas zonas, sino en todo el territorio nacional, en materia económica y social.

Durante el último siglo, Colombia ha mantenido unos actores económicos fijos en cada mandato que se han convertido en la esencia misma de la economía y fisco colombiano. Hasta mediados del siglo XX, el impuesto sobre aduanas, fue el principal tributo de las políticas fiscales; durante el transcurrir de estos años, se consolidaron políticas más estructuradas, por medio de diferentes mecanismos, pero la tendencia siempre fue, la creación de nuevos tributos, el incremento de las bases gravables, la ampliación de las tarifas impositivas y la disminución de las exenciones, unido a su vez con la lucha contra la elusión y la evasión fiscal a finales del siglo.

Posteriormente, el impuesto a la renta se convirtió en el principal tributo nacional. La creación del impuesto a las ventas, el impuesto a las transacciones financieras, el sistema general de participaciones, el mecanismo de retención en la fuente, las transferencias con destinación específica y el proceso de descentralización entre entidades del orden nacional al regional y municipal, enmarcan las políticas actuales y muy seguramente las de los futuros años (Robinson y Urrutia, 2012). 


\section{EXPERIENCIAS EN LA RECONSTRUCCIÓN ECONÓMICA REGIONAL Y SECTORIAL}

Históricamente los planes de desarrollo de cualquier Estado, han sido el medio para alcanzar el desarrollo nacional, por lo tanto, una revisión de algunos países en desarrollo que han alcanzado un desarrollo económico considerable a través de la reconstrucción regional y el fortalecimiento de la producción interna, generando en ellos abastecimiento de bienes y servicios propios, permitiendo de igual manera impulsar y promover el desarrollo de las exportaciones.

En El Salvador, el tema agrario fue motivo igualmente de conflictos sociales donde la expulsión de comunidades campesinas del acceso a la tierra generó el levantamiento campesino de los años treinta. Tras la firma del acuerdo de paz en 1992 se impulsó la reactivación del sector agrícola y la formación de unidades productivas rentables, facilitando oportunidades de crédito, saneamiento financiero, renovación de infraestructura, incorporación tecnológica, reconversión y transformación productiva, así como de comercialización (Flores, 1998). El fomento de la agricultura individual en el sector cooperativo permitió establecer formas de propiedad asociativa que incluyeron participación real a través de combinación entre la propiedad colectiva y la individual, al tiempo que se creó el banco de tierras para promover y financiar las transacciones de compra-venta de pequeñas propiedades rurales con el ánimo de financiar a campesinos y pequeños agricultores, la compra de tierras cultivables; como resultado de este proceso se distribuyeron más de 295.000 hectáreas la mayor parte en forma de cooperativas, lo que beneficio a más de 85.000 familias campesinas.

De igual forma, Guatemala a través de un complejo proceso de negociaciones por la paz entre el ejército y la Unidad Revolucionaria Nacional Guatemalteca (URNG), realizaron acuerdos sobre aspectos socioeconómicos y agrarios que abarcaron de forma estratégica elementos como la posesión de la tierra; la sostenibilidad y el uso de los recursos naturales; las estructuras de financiación; la transformación y la comercialización; las relaciones laborales; la asistencia técnica y la organización de la población rural, logrando Impactos positivos en el desarrollo productivo y comercial, hecho que fortaleció la institucionalidad pública y privada del sector, y generó un clima favorable para la inversión agroindustrial identificando nuevos productos de exportación y financiando a través de programas creados por el ministerio de Agricultura, Ganadería y Alimentación (MAGA) a aquellos productores con probabilidades de éxito en el mercado de la exportación que generaran cadenas productivas comerciales (Murga, 2007).

En el continente asiático, Corea del Sur se ha destacado por una industrialización en cuatro etapas: la primera de ellas la reconstrucción, seguida por el fomento de exportaciones, el progreso de la industria pesada y finalmente la etapa de estabilidad, liberación y crecimiento equilibrado. Lo anterior permitió la creación de zonas industriales, desarrolladas para exportar, y asegurar el crecimiento proporcionado de las comunidades lugareñas. Se tuvo en consideración zonas específicas para la industria textil, electrónica y mecánica con características que combinaban a estos tres sectores y otras zonas destinadas a la industria química e industria pesada en donde la mayoría del financiamiento para las empresas provino de inversiones del exterior; es de resaltar que este país destinó un rubro importante al sistema educativo dentro de su política social, preparando al recurso humano para absorber la tecnología avanzada del exterior y que 
los empresarios coreanos adoptaron mejorando su productividad (Hyun, 1992). Taiwan, también se desarrolló por etapas, iniciando con el incremento de industrias básicas mediante la sustitución y limitación de importaciones de bienes de capital, impulsando su economía con excedentes que le permitieron fortalecer las exportaciones y conseguir la actuación del gobierno en el comercio y el autofinanciamiento de la industria, esto en su fase final permitió incrementar el comercio y mantener el liderazgo en la exportación de productos tradicionales como textiles y otros propios de las maquiladoras; así mismo concentró su reforma en el sector agrícola, donde se destaca la inversión del gobierno en el desarrollo de infraestructura, industria pesada y también la estimulación de pequeñas y medianas empresas en la fabricación de bienes de consumo. Corea del Sur y Taiwán adoptaron un sistema que reforzó su volumen industrial con base en la exportación de manufacturas. También tuvieron como complemento políticas intervencionistas, obteniendo amplios subsidios del sector financiero y estímulos tributarios a la inversión en zonas escogidas como prioritarias Hyun, 1992). Considerada hoy como una de las economías más abiertas de Asia, Singapur debe su éxito en gran parte a su ubicación geográfica estratégica, a la activa intervención del gobierno y a una política educativa con la cual logró asimilar las nuevas tecnologías y superar la carencia de mano de obra nacional. Singapur mediante un proyecto de integración regional fundado en la idea de complementariedad del comercio, las manufacturas y el turismo incremento su importancia regional con 14 zonas libres maximizando sus probabilidades de progreso y desarrollo generando más de 105.000 empleos (Hyun, 1992).

Un elemento común que destaca en el progreso de estos países son las llamadas zonas libres, que acompañadas de políticas económicas promovieron las exportaciones de productos manufacturados. Para finalizar con lo expuesto por Hyun (1992), el éxito de las zonas libres se basó en la suficiencia administrativa y la aplicación de políticas por parte del estado las cuales dieron lugar a una industrialización que permitió transformar materias primas importadas y promover exportaciones manufactureras.

\section{INCENTIVOS TRIBUTARIOS A LA INVERSIÓN EN CENTROAMÉRICA}

Medina Bermejo (2016) muestra las tendencias que se dan con más frecuencia respecto a la creación de incentivos fiscales para atraer la inversión y concluye que dentro de estos predomina la creación de zonas de libre comercio y zonas francas y se estimula la exportación de bienes y servicios, el turismo y el aprovechamiento de recursos no renovables. Sin embargo, identifica factores negativos que afectan el éxito las políticas de incentivos, uno de estos es la deficiencia de una proyección a largo plazo, ya que muchos de esos incentivos corresponden a políticas de los gobiernos de turno y que no existe un objetivo claro que permita desarrollar la capacidad competitiva y el avance continuo. Otro factor que identifica, es la falta de capacitación del capital humano, de inversión en infraestructura tanto física como social, del robustecimiento del mercado de valores y de políticas de seguridad general que han entorpecido los resultados esperados de una $u$ otra forma.

Por lo anterior, Medina Bermejo (2016) plantea que es necesario que los gobiernos modifiquen su visión a largo plazo y adecuen zonas específicas para el desarrollo industrial, inviertan en la formación técnica y tecnológica del capital humano y promuevan la protección del medio ambiente todo esto ligado a estrategias que 
garanticen la seguridad y permitan el incremento de la productividad y rendimiento de los inversionistas. En distintos momentos de su historia, las naciones promueven incentivos para generar desarrollo económico sostenible, basando sus estrategias en el apoyo de la industrialización con miras a la exportación, la mejora de la infraestructura física y social, el aprovechamiento de recursos predominantes en cada uno de los países, así como la inversión en el talento humano; todos estos factores pueden estar dimensionados en las políticas fiscales de cada una de las regiones.

En el territorio nacional colombiano, la aplicación de este tipo de políticas fiscales de desarrollo históricamente se ha centrado en la recuperación económica de zonas afectadas por desastres naturales los cuales sentaron precedentes para analizar distintas experiencias alcanzadas durante su aplicación. En el año 1996, sobre todo los departamentos de Huila y Cauca, se promulgó la Ley Páez $($ Ley 218, 1995) que planteó la exención en el impuesto de renta por un periodo de diez años para empresas que fueran constituidas dentro de los municipios allí enunciados, con lo cual el gobierno, buscaba incentivar la creación de empleo, aumentar las importaciones de activos fijos, insumos y repuestos para dichos municipios, así como también liberar de impuestos sobre las importaciones que se realizaran.

Antes de la denominada Ley Páez, la industria caucana no estaba diversificada y el subsector que más contribuía al Valor Agregado Industrial (VAI), era la fabricación de maquinaria y aparatos electrónicos. Posteriormente en 1997, aparecen nuevos subsectores destacando la elaboración de alimentos y bebidas, la fabricación de papel, cartón, sus derivados, así como la fabricación de productos de caucho y plástico, fabricación de químicos, edición e impresión y grabaciones.

A diciembre de 2005, 139 empresas se encontraban registradas como beneficiarias de esta ley donde cerca el 68\% correspondían al sector manufacturero y el $18 \%$ al sector agrícola generando aproximadamente 4.873 empleos directos. Cada uno de los subsectores anteriormente mencionados son un complemento en la estructura productiva de la industria manufacturera caucana y explica el crecimiento que presenta el sector (Alonso \& Lotero, 2008). Al terminarse la duración de los beneficios tributarios de la Ley Páez y con el deseo de fomentar las actividades económicas en la zona, el gobierno nacional expidió el Decreto 780 de 2008 que permitió a las empresas beneficiarias de la mencionada Ley, migrar al régimen de zonas francas (Peña, 2017).

La Ley Quimbaya (Ley 608, 2000) pretendía ser una herramienta para la reactivación y reconstrucción económica y social del Eje Cafetero, cuyo principal beneficio era exonerar del impuesto a la renta por diez años. Se implementa además el Plan de desarrollo (20012003) "Quindío para vivirlo", cuya estrategia en el desarrollo integral sostenible y competitivo de la actividad empresarial. Se centraba en transformar al Quindío en un exportador a través de la implementación de ciencia y tecnología acercando el sector agrícola a la agroindustria lo que en parte frenó la caída de este sector. Sin embargo, el rumbo del crecimiento se fue dispersando hacia el sector turístico viendo en él un gran potencial. Valencia (2002) advierte que: "Esta Ley por sí sola no generaría la reactivación económica" (pág. 33), ya que ésta dependía también de acciones que se identificaran para las "otras partes que componían el problema, especialmente la crisis cafetera". (Montoya, 2013, p. 27). 
Es necesario resaltar que no existió una política o programa nacional dentro de la coyuntura de la emergencia enfocada a recuperar este sector agrícola, teniendo en cuenta que la economía en esta región era altamente dependiente de dicho producto; las políticas que pudieron haber apuntado hacia al desarrollo de la industria, la ciencia y la tecnología se redujeron a programas que no superaban en recursos los destinados a impulsar el turismo, por ende no existió un atractivo real para industrias y empresas de servicios especializados (Montoya, 2013).

\section{LA RECONSTRUCCIÓN DE TERRITORIOS AFECTADOS DIRECTAMENTE POR EL CONFLICTO ARMADO}

Las ZOMAC son el conjunto de municipios que se han considerado como más afectados por el conflicto armado, definidos conforme a la Ley 1819 del 2016 (Art. 236) y en cuya jurisdicción aplicarán las disposiciones establecidas en los artículos 235 al 237 de la misma Ley, reglamentados por el Decreto 1650 del 2017, el cual estipuló la lista de municipios que se hicieron acreedores de dicha definición y los requisitos mínimos de inversión y generación de empleo para las nuevas empresas que se constituyan bajo esta figura en dichos municipios.

Los incentivos en el impuesto de renta propuestos han establecido para las micro y pequeñas empresas que se constituyan y generen empleo, una tarifa del $0 \%$ hasta el año 2021; 25\% hasta el año 2024; 50\% hasta el año 2027 y de ahí en adelante del 100\%; equivalentemente la empresas medianas y grandes contaran con estos beneficios, tributando inicialmente a la tarifa del 50\% hasta año 2022; posteriormente del 75\% hasta año 2027 y en adelante del 100\%. Un aspecto interesante de esta ley es que excluye de estos beneficios a empresas dedicadas a la minería y la explotación de hidrocarburos, esto porque se consideró que las inversiones en estas áreas no están necesariamente condicionadas por temas de incentivos tributarios.

Si bien es cierto que esta ley brinda la oportunidad de formalizar empresas, no solo del sector agrícola sino también del sector servicios, turístico, entre otros, la falta de garantías debido a la evolución del proceso de paz, provoca que grandes capitales duden en invertir en estos territorios, Sin embargo, su crecimiento y consolidación son factores clave para mejorar las condiciones de vida de la población e incrementar el ingreso per cápita del país. Por otra parte, el Decreto 1915 de 2017, reglamentó el mecanismo de pago "obras por impuestos", dando la posibilidad a los contribuyentes en Colombia de extinguir las obligaciones tributarias del impuesto sobre la renta a cambio de elegir un proyecto de interés social en las Zonas Más Afectadas por el Conflicto Armado (ZOMAC), y aportar directamente recursos para la ejecución de dicho proyecto y de esta forma pagar parcialmente el impuesto de renta a cargo.

Esta se convierte en una gran oportunidad que tienen los contribuyentes, para que sean ellos mismos quienes transfieran el dinero directamente a estos proyectos, sin tener que entregarlos al tesoro nacional por intermedio de la DIAN. Este mecanismo es sin duda un camino viable para mejorar la infraestructura pública de estos municipios y reconstruir el tejido social a través del acceso a servicios públicos básicos, educación e infraestructura vial, conectando de esta forma a las empresas en las ZOMAC con las cadenas productivas y comerciales, favoreciendo la producción y el desarrollo de todo el país. 
El municipio de Aguachica (Cesar), históricamente ha vivido el flagelo del conflicto armado interno colombiano; por tal razón fue contemplado como ZOMAC, siendo un territorio con una base productiva, aprovechable para el desarrollo económico sostenible. ¿Cómo surgen estas zonas? Según Bravo (2015), durante "La Violencia", las zonas rurales fueron el campo de batalla; este conflicto afectó mayoritariamente la población pues aumentó el crimen y la propiedad sobre la tierra fue despojada, generando desconfianza entre el mismo pueblo y las instituciones gubernamentales. Según Gutiérrez (2015), la guerra aumentó la brecha de desigualdad de los campesinos; adicionalmente, la falta de normas legales incluyentes para el campesinado, aportaron a la pérdida de interés en el sector agrario en Colombia durante los primeros años de la década de 2000.

En consecuencia, el conflicto interno colombiano no ha generado la suficiente confianza para el empresario respecto a seguridad y estabilidad, por el contrario, ha sido nocivo alejando capital del país tanto de inversión local como de inversión internacional lo cual no ha permitido un desarrollo económico sostenible en especial de la agroindustria en el campo. Sin embargo, el 24 de noviembre de 2016 el Gobierno Nacional y las FARC-EP, firmaron el acuerdo para terminar el conflicto, concluyendo de manera definitiva un conflicto con una de las partes, que se extendió por más de cincuenta años. Cabe insistir que la paz es considerada un derecho humano superior, siendo esencial para poder ejecutar los demás derechos y deberes de los individuos, su eje central en Colombia ha sido contribuir con el actuar del Estado en todo el país, particularmente en aquellas regiones históricamente abandonadas.

El Acuerdo Final contiene la "Reforma Rural Integral" cuyo objetivo es contribuir con cambios de estructura en el campo, permitiendo la disminución de las diferencias entre la ciudad y el campo, creando mejores condiciones para el bienestar de la población campesina. Dichas condiciones comprenden planes nacionales que buscan el mejoramiento de la infraestructura y adecuación de tierras, desarrollo social, estímulos a la producción agropecuaria, asistencia técnica, subsidios y créditos para la generación de ingresos, formalización laboral rural, mercadeo y asociatividad. Este enfoque territorial analiza las necesidades y características de los lugares y pobladores, para desarrollar sostenibilidad, pretendiendo de esta forma integrar territorios, disminuir la pobreza, generar igualdad y garantizar los derechos ciudadanos.

\section{ANÁLISIS SITUACIONAL DEL MUNICIPIO DE AGUACHICA}

Ubicado en el departamento del César, el acceso está dado por las vías Santa Marta Aguachica, la troncal del Magdalena Medio o la vía Bogotá - Bucaramanga - Aguachica, de esta vía se desprenden las vías Aguachica - Ocaña y Aguachica - Gamarra; existen carreteables que comunican Aguachica con el resto de las veredas, pero se encuentran en estado de deterioro y abandono (Alcaldía del municipio de Aguachica, 2016). El acceso por vía aérea está dado por el aeropuerto Hacaritama, en actual estado de deterioro. El río Magdalena es el canal fluvial de transporte utilizado por pasajeros que provienen o se dirigen al sur del departamento de Bolívar.

Su economía está enfocada en el sector agropecuario, la agroindustria y el comercio. A través de estos han surgido servicios como agro técnicos, financieros, transportes y servicios tanto empresariales como personales, dirigidos a toda la población de la región. 
Ya que el sector agrícola es el principal en la zona, tener un acertado conocimiento del clima y características del suelo, es esencial para identificar épocas de siembra, antecedentes de inundaciones y derrumbes, así como la selección de las especies agronómicas y forestales que pueden ser incorporadas a la región. La zona del municipio de Aguachica cuenta los pisos térmicos templado y cálido. En cuanto a su geografía, cuenta con zona montañosa al norte, una zona de llanura al sur, bañada por diferentes cuerpos de agua. Cuenta con selva tropical, la cual hoy en día se ha visto afectada en su extensión debido a la expansión de la actividad agrícola que usa las talas y quemas de la selva para acondicionar los terrenos y explotarlos. También cuenta con una selva tropical sub-andina desarrollada en la ladera de la cordillera occidental, protegida por la Ley 2 de 1959. En cuanto a la población, según el registro oficial de la Alcaldía municipal, la población es de 93.917, siendo el rango de mayor población el de los 15 a los 44 años de edad.

Según el Plan de Desarrollo "Aguachica Incluyente y en Paz 2016-2019", las actividades con mayor presencia en Aguachica y sus alrededores son la ganadería, dentro de la cual se encuentra la explotación bovina, además de la bufalina, equina y algunas especies menores como los porcinos, caprinos y ovinos; la producción lechera cuenta con 132 empresas registradas en las cámaras de comercio de Valledupar y Aguachica. En cuanto a la práctica agrícola, se resalta la existencia de suelos fértiles que permiten la producción de cultivos tales como el fríjol, café, maíz, yuca, cacao, maracuyá, plátano, algodón, sorgo, arroz, palma de aceite, mango entre otros; los dos cultivos más representativos son la palma de aceite y el café, en primer y segundo lugar respectivamente. La pesca, es la principal fuente de ingresos de los habitantes de corregimientos ribereños sobre los márgenes de los ríos Magdalena y Lebrija con sus ciénagas, allí se producen especies nativas como el bocachico, blanquillo, doncella, dorada, pacora, bagre besote y demás; que se han visto diezmadas por las prácticas inadecuadas, el calentamiento global que produce la disminución de los niveles en los cuerpos de agua y la falta de control en el momento de la captura frente al tamaño afectando así la población de peces.

La violencia en el "Magdalena Grande" (César, Magdalena y La Guajira), ha viajado desde la época de la violencia bipartidista, muchas personas que emigraron del centro del país, poblaron dichas tierras (Montes, Martínez y Martínez, 2014a). En Aguachica hicieron presencia las Autodefensas Unidas de Colombia (AUC), la guerrilla de las FARC-EP (Fuerzas Armadas Revolucionarias de Colombia Ejército del Pueblo) y la guerrilla del ELN (Ejército de Liberación Nacional) así como el EPL (Ejército Popular de Liberación), donde factores como el área total del Cesar y sus departamentos vecinos, así como y sus economías explican la presencia de diferentes actores armados en la zonza (Arias, 2010a). Las FARC-EP, inician su presencia en la región de la costa caribe colombiana con el frente IV a mediados de 1972, buscando llegar a la sierra nevada de Santa Marta y a la serranía del Perijá como medida estratégica dentro del conflicto. Según Arias (2010b):

En la década de 1970 ingresaron las Farc y, posteriormente, el ELN. Estas dos agrupaciones comenzaron a apoderarse del departamento. A finales de la década de 1980 llegaron los paramilitares al sur del Cesar, ayudados por las autodefensas del Magdalena Medio. Esta confluencia de grupos convirtió a la región en zona de guerra, donde predominaron los asesinatos selectivos, las masacres y los desplazamientos. En contraposición, la economía local se vino a pique debido al 
abandono de las actividades legales vinculadas al campo: la ganadería y la agricultura. (p. 34)

En cuanto al ELN, el frente Juan Manuel Martínez Quiroz ocupó la parte baja y alta del departamento del César, al mando de alias "Milton" o "Jacobo", según Montes et al. (2014c):

A modo de síntesis: las organizaciones guerrilleras coparon las zonas bajas y altas del Magdalena Grande entre los años 80 y 90, posteriormente empezaron a movilizarse hacia las zonas altas por la constante aparición de las AUC. Como consecuencia de estas disputas territoriales la población civil sufrió con sevicia la capacidad ofensiva de los actores armados y su lucha constante por posesionarse y ejercer el control territorial, situación que desembocó en masacres, desplazamientos forzados, asesinatos selectivos, secuestros y expropiaciones. (p. 26)

A finales de la década de los años 80, las autodefensas aumentan su presencia en la zona. Según Montes et al. (2014d) promovidas por sectores como ganaderos, bananeros y latifundistas afectados por las extorsiones y recuperaciones de tierra que llevaban a cabo los grupos guerrilleros. En cuanto a las acciones bélicas perpetradas, Aguachica fue uno de los primeros municipios al sur del César que fue afectada por la acción de las guerrillas y los paramilitares. Según Montes et al. (2014e), a partir de 1988 se presentaron masacres por parte de los paramilitares en Aguachica. En la década de los años 90, las masacres siguieron en municipios de la zona, pero con mayor predominio en Aguachica y San Alberto ya que el ELN había convertido a Aguachica en el centro de su accionar. Según el Centro Nacional de Memoria Histórica (2017), en el municipio de Aguachica ocurrieron 281 casos de desaparición forzada entre 1970 y 2013, cometidos por los diferentes grupos armados al margen de la ley que hicieron presencia en el territorio, no solamente las guerrillas y los paramilitares sino también grupos internos que se disputaban el control del contrabando de mercancía y narcotráfico, consolidándose en la parte alta del municipio y ejerciendo así un control total, apoderándose de las instituciones públicas de la región.

Según Medina Gallego (2011), el departamento del César por ser una economía agrícola, ganadera y con presencia de industria petroquímica. Además, cuenta con importantes recursos carboníferos; factores que necesariamente fueron vistos como forma de financiación por parte de los actores armados de la región. El 27 de agosto de 1995 en este municipio ocurre el asesinato del médico José Padilla, destacado miembro de la comunidad. A raíz de esto, se organizaron asambleas donde con el apoyo de la población, se determinaron las acciones para hacer frente a las acciones violentas. Dentro de estas intervenciones, se sugirió la realización de una consulta popular, mecanismo de participación establecido en la Constitución de 1991. La consulta surtió efecto y la violencia se redujo, lastimosamente la ejecución de obras de infraestructura y acompañamiento se terminó debido a las investigaciones del proceso 8000 contra el presidente de turno, Ernesto Samper. Sin embargo, Aguachica se consolidó como el primer municipio que implementó un modelo de paz, y demostró que son los habitantes las piezas claves para la transformación pacífica de los territorios.

Se observa que la seguridad y el orden público en el municipio de Aguachica, se encuentra en un estado de sensibilidad, afectando las condiciones de mercado, teniendo 
en cuenta el riesgo que implica realizar inversiones en dicho territorio. Por el flagelo de la guerra que ha vivido históricamente a mano de diversos grupos armados colombianos, el municipio de Aguachica fue incluida dentro de las denominadas ZOMAC, lo cual se constituye en una gran oportunidad para que generar un desarrollo sostenible en esta región, favoreciendo a sus habitantes en cuanto a la formalización de las actividades productivas, mejorando de esta forma la calidad de vida, los niveles de ingresos y la inversión tanto pública como privada en el municipio.

Por otro lado, Aguachica requiere mejorar la infraestructura vial, con énfasis en las vías terciarias que comunican las veredas con el centro urbano. De esta manera, se favorece el adecuado transporte de las mercancías, con miras a la participación en las cadenas productivas nacionales. De igual manera, es necesario garantizar incentivos, apoyo técnico y campañas para la disminución del calentamiento global, que se constituyen en ayudas oportunas para todos los pequeños productores de la región, con el fin de garantizar un verdadero desarrollo social y económico sostenible en el tiempo. Al clasificar al municipio como ZOMAC, se estimula a algunas empresas se establezcan en Aguachica con el fin de acceder al beneficio, favoreciendo a la generación de puestos de trabajo en la zona. Otro de los beneficios de las ZOMAC, es que no tiene prohibición alguna la liquidación de empresas ya existentes y la constitución de nuevas, situación que si sucedía con la Ley 1429 de 2010. Por tal razón, es muy probable que en la actualidad la dinámica empresarial se vea fortalecida por estos incentivos en las ZOMAC. Del mismo modo, favorece la formalización de negocios, teniendo en cuenta que el beneficio de las ZOMAC contempla la formalización de las actividades que se han llevado de manera informal y de esta forma, se empiecen a crear relaciones comerciales entre los diferentes productores, consumidores e intermediarios propios de la región, permitiendo iniciar el modelo de desarrollo sostenible en la propia zona.

Dada la necesidad de mejorar la infraestructura vial del municipio y sus veredas, el régimen ZOMAC contempla también en este aspecto en el artículo 238 de la Ley 1819 de 2016. En este se establecen los requisitos y condiciones para que las empresas que sean beneficiarias del régimen puedan cancelar hasta el 50\% del impuesto a cargo determinado en la declaración de renta, a través de la destinación de esos recursos a la inversión en obras trascendentes para el municipio, estos proyectos deberán encontrarse aprobados por la Agencia para la Renovación del Territorio y con visto bueno del Departamento Nacional de Planeación. Esta inversión favorece también las obras de suministro para agua potable, alcantarillado, energía, salud y educación. Que la comunidad cuente con estos beneficios, genera un impacto directo en la calidad de vida de sus habitantes; por tal razón se resalta la importancia de que sean los residentes del municipio de Aguachica quienes formalicen sus actividades, se agremien, asocien y construyan por si mismos el desarrollo de su región, ya que son los principalmente beneficiados y quienes pueden lograr que todos estos beneficios estén presentes en su municipio y veredas por más de los diez años.

Las características vocacionales y culturales, además de una importante ubicación geográfica, hacen del municipio de Aguachica una zona estratégica para el desarrollo comercial interdepartamental con fines de exportación de tres departamentos: Santander, Norte de Santander y Cesar. Por lo anterior, se debe contemplar la necesidad de una gran zona franca agropecuaria, que se convierta en alternativa para importar 
tecnología hacia el sector, promover el desarrollo agroindustrial y dinamizar las actividades agrícolas, pecuarias y pesqueras de toda la región, aprovechando su ubicación geográfica para conectar el centro y suroccidente del país con la costa norte. Desde el punto tributario, es importante hacer coherente la política fiscal nacional, con la política local tributaria y de desarrollo, con una asertiva política de contraloría y educación para hacer a Aguachica uno de los municipios más importantes de la zona nororiental del país, por lo que se deben revisar los impuestos municipales de industria y comercio, impuesto predial, entre otros; en armonía con el propósito de avanzar en un desarrollo socioeconómico en condiciones de sostenibilidad.

\section{CONCLUSIONES}

La política fiscal en Colombia, ha estado direccionada en el incremento de los ingresos nacionales y no en la gestión del gasto público. Si se compara el comportamiento desde los años veinte a la actualidad, las medidas para reformar bases gravables, tarifas impositivas y sujetos pasivos han sido el factor común de los gobiernos en cada período. Con relación al desarrollo económico nacional, el conflicto armado ha sido una de las causas principales para que muchas regiones a lo largo del territorio nacional hayan quedado en el olvido, relegadas a un segundo plano y con altos niveles de inequidad frente a los grandes centros urbanos y regiones menos golpeadas por este flagelo.

El municipio de Aguachica, clasificada como ZOMAC, puede constituirse en el punto de partida para iniciar el proceso para reducir la brecha de desigualdad económica y social. Para ello, se hace necesario implementar políticas y mecanismos para que los habitantes de esta zona sean los mayores beneficiarios, y además sus residentes puedan contribuir al desarrollo sostenible de la zona. Pero no sólo el Gobierno Nacional forma parte de este esfuerzo: los gobiernos regionales y municipales, deben orientar sus políticas de manera conjunta para poder promover mejoras en la zona, con el fin de atender las necesidades identificadas como la inversión vial, capacitación técnica e incentivos para el desarrollo y el fortalecimiento de las actividades productivas.

La diversidad de suelos y temperaturas de la zona, favorecen la participación en diferentes actividades económicas, principalmente el agro y la ganadería. Pero estas deben potenciarse de manera amigable con el ambiente. Para el caso de Aguachica, las políticas deben favorecer el uso responsable de recursos, como medio para generar el desarrollo sostenible necesario conforme a las características particulares del municipio. Ahora bien, con respecto a la sostenibilidad del desarrollo un factor a tener en cuenta es la expansión de la frontera agrícola, puesto que Aguachica ha incrementado dicha frontera, afectando así la selva nativa, y con esta fauna y flora propias de la región e irrecuperables, la ciudadanía, el municipio, el departamento y el Estado deben solidariamente velar por el buen manejo, destinación y protección de los recursos naturales. Lo anterior, tiene particular relevancia si se consideran las generaciones futuras, y además que el daño ambiental puede en muchas situaciones ser irreversible y que afecta igualmente el nivel de vida de cada una de las personas que componen la sociedad. 


\section{REFERENCIAS}

Alonso, J.C. \& Lotero, A.M. (2008). Ley Páez y el nivel de actividad económica. En 10 años de la ley Páez: Transformación de la economía caucana. Bogotá: Universidad ICESI. Recuperado de: http://www.icesi.edu.co/cienfi/images/stories/Ley Paez.pdf

Arias, A. (2010). Monografía político electoral departamento del César (1997 a 2007). Recuperado de https://moe.org.co/home/doc/moe mre/CD/PDF/cesar.pdf

Banco de la República (2017). Política Fiscal. Recuperado de http://enciclopedia.Banrep.cultural.org/index.php/Pol\%C3\%ADtica fiscal

Banco de la República. (2013). ¿Qué es la política fiscal? Recuperado de http://www.banrep.gov.co/es/contenidos/page/qu-pol-tica-fiscal

Bangs, R. S. (1971). Política fiscal para los países que inician su desarrollo. México: Fondo de Cultura Económica.

Bravo, A. M. (2015). Fragmentos De La Historia Del Conflicto Armado (1920-2010). Contribución al entendimiento del conflicto armado en Colombia. Comisión del conflicto y sus víctimas. Recuperado de http://www.altocomisionadoparalapazgov.co/mesadeconversaciones/PDF/fragmentos-de-lahistoria-del-conflicto-armado-1920-2010-1447167631-1460380435.pdf

Centro Nacional de Memoria Histórica (2017). Memoria de la infamia. Desaparición forzada en el Magdalena Medio. Bogotá: CNMH.

Consejo Municipal de Aguachica (2016). Acuerdo Plan de Desarrollo Municipal. Recuperado de http://www.aguachica-cesar.gov.co/index.shtml?x=2917644

Flores, M. (1998). El Salvador: Trayectoria de la reforma agraria, 1980-1998. Revista Mexicana De Sociología, 60(4), 125-151. Doi: 10.2307/3541334

Gutiérrez Sanín, F. (2015). ¿Una historia simple? Contribución Al Entendimiento Del Conflicto Armado En Colombia. Comisión Histórica Del Conflicto Y Sus Víctimas. 1-43. Recuperado de http://www.altocomisionadoparalapaz.gov.co/mesadeconversaciones/PDF/una-historia-simple1447167162-1460380556.pdf

Hyun, L. K. (1992). De Los Cuatro Tigres Asiáticos. Comercio Exterior, 42(2), 177-181. Recuperado de http://revistas.bancomext.gob.mx/rce/magazines/255/7/RCE7.pdf

Medina Bermejo, A (2016). La eficacia de los incentivos tributarios a la inversión en Centroamérica. Recuperado de http://icefi.org/sites/default/files/icefi ints laeficacia.pdf

Medina Gallego, Carlos (2011). FARC-EP Flujos y reflujos - La guerra en las regiones. Bogotá: Editorial Kimpres Ltda.

Mesa de Conversaciones (2016). Acuerdo Final para la Terminación del Conflicto y la Construcción de Una Paz Estable y Duradera. Bogotá. Recuperado de http://www.altocomisionadoparalapaz.gov.co/herramientas/Documents/Acuerdo-Final-AFweb.pdf

Montes, C. A., Martínez, G. L., \& Martínez, G. N. (2014). Memorias y narrativas: tres décadas del conflicto armado en el magdalena grande. Recuperado de https://ebookcentral.proquest.com

Montoya Rodríguez J.S. (2013) Análisis de la incidencia de la formulación e implementación de la ley 608 del 2000 (ley Quimbaya) en el departamento del Quindío (periodo 2000-2005) bajo el enfoque de las políticas públicas. Universidad Colegio Mayor de Nuestra Señora del Rosario.

Municipio de Aguachica - César (2016). Nuestro Municipio. Recuperado de: http://www.aguachicacesar.gov.co/informacion general.shtml

Murga, J. (2007). La cuestión agraria 10 años después de la firma de la paz. Recuperado de http://www.albedrio.org/htm/documentos/JorgeMurga-001.pdf

Peña Preciado, A. (2017). El comercio exterior como una herramienta de sostenibilidad para las Zonas más Afectadas por el Conflicto Armado (Zomac). Instituto Colombiano de Derecho Tributario, 
76(1), 265-284. Recuperado de http://www.icdt.co/publicaciones/revistas/Revista76/art8/Revista76 art8.pdf

Robinson, J. \& Urrutia, M. (2007). La política fiscal en el siglo XX en Colombia. En Robinson, J. \& Urrutia, M. Economía colombiana del siglo XX: Un análisis cuantitativo. Bogotá.

Unidad para las Víctimas. (2016). Aguachica, en el Cesar, se anticipó 21 años a plebiscito por la Paz. Recuperado de http://www.unidadvictimas.gov.co/es/reparaci\%C3\%B3n/aguachica-en-elcesar-se-anticip\%C3\%B3-21-a\%C3\%B10s-plebiscito-por-lapaz/17137 